"The submitted manuscript has been authored by a contractor of the U.S. Government under contract No. DE-AC05-96OR22464 Accordingly, the U.S. Government retains a nonexclusive, royalty-free license to publish or reproduce the published form of this contribution, or allow others to do so, for U.S. Government purposes."

$$
\text { CONF- } 960850--14
$$

\title{
Test of Two Prototype High-temperature Superconducting Transmission Cables*
}

\author{
By \\ J. W. Lue, M. S. Lubell, \\ D. M. Kroeger, and P. M. Martin \\ Oak Ridge National Laboratory \\ Oak Ridge, Tennessee \\ J. A. Demko and E. C. Jones \\ Oak Ridge Associated Universities \\ Oak Ridge, Tennessee \\ Uday Sinha and R. L. Hughey \\ Southwire Company \\ Carrollton, Georgia \\ 1996 \\ Presented at the \\ Applied Superconductivity Conference \\ Pittsburgh, PA \\ August 25-30, 1996 \\ Prepared for the \\ Fusion Energy Division \\ (AK 0600000$)$ \\ Prepared by the \\ Oak Ridge National Laboratory \\ Post Office Box 2008 \\ Oak Ridge, TN 37831-6285 USA
}

DISTREUTION OF THS DOCUAENT IS UMLMITED

Managed by

LOCKHEED MARTIN ENERGY RESEARCH, Inc.

for the

U.S. DEPARTMENT OF ENERGY

under contract DE-AC05-960R22464

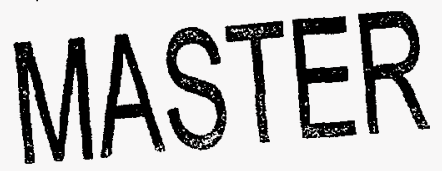

\footnotetext{
* Research performed under a CRADA between Sourthwire and ORNL, the latter is sponsored by the Office of Energy Efficiency and Renewable Energy, U.S. Department of Energy under contract DE-AC05-960R22464 with Lockheed Martin Energy Research, Inc.
} 


\section{DISCLAIMER}

Portions of this document may be illegible in electronic image products. Images are produced from the best available original document. 


\section{DISCLAIMER}

This report was prepared as an account of work sponsored by an agency of the United States Government. Neither the United States Government nor any agency thereof, nor any of their employees, makes any warranty, express or implied, or assumes any legal liability or responsibility for the accuracy, completeness, or usefulness of any information, apparatus, product, or process disclosed, or represents that its use would not infringe privately owned rights. Reference herein to any specific commercial product, process, or service by trade name, trademark, manufacturer, or otherwise does not necessarily constitute or imply its endorsement, recommendation, or favoring by the United States Government or any agency thereof. The views and opinions of authors expressed herein do not necessarily state or reflect those of the United States Government or any agency thereof. 


\title{
Test of Two Prototype High-Temperature Superconducting Transmission Cables
}

\author{
J. W. Lue, M. S. Lubell, E. C. Jones, J. A. Demko, D. M. Kroeger, and P. M. Martin \\ Oak Ridge National Laboratory, Oak Ridge, TN 37831-8071 USA \\ Uday Sinha and R. L. Hughey \\ Southwire Company, Carrollton, GA 30119 USA
}

\begin{abstract}
Two 500-A class prototype high-temperature superconducting cables have been constructed by Southwire Company and tested at Oak Ridge National Laboratory (ORNL). In the first cable, no insulation was used to separate the individual HTS tapes. In the second cable, Kapton tape was used to insulate the HTS tapes between successive layers for the study of AC loss and current distribution. The cables were tested with both $\mathrm{DC}$ and $\mathrm{AC}$ currents in liquid nitrogen from 77 to $69 \mathrm{~K}$. Both cables achieved DC critical current, $I_{c}$ greater than 500 A. A calorimetric technique that measures the cable temperature rise under ac currents was used to measure the ac loss of the cables. The un-insulated cable showed a cryoresistive behavior under the $60 \mathrm{~Hz} \mathrm{AC}$ currents. The insulated cable started to show measurable ac loss at current where there was corresponding DC resistive voltage.
\end{abstract}

\section{INTRODUCTION}

During the initial phase of the CRADA between ORNL and Southwire Co. to develop High-Temperature Superconducting (HTS) underground transmission cable, two 500-A class prototype cables were constructed[1]. The cables, as well as short samples of the Bi-2223/Ag HTS tapes were tested systematically at ORNL.

The cables were tested with both $\mathrm{DC}$ and $\mathrm{AC}$ currents in liquid nitrogen. Both cables achieved design currents, however, substantial degradation in comparison to the short sample $I_{c}$ 's was observed. A simple calorimetric technique was used to measure the ac losses of the cables. A method of utilizing the broad resistive transition of the HTS cable was devised to calibrate the ac loss. Reasonably low ac loss was measured on the insulated cable.

\section{SHORT SAMPLE TESTING}

A series of short sample tests were performed on the Bi2223/Ag HTS tapes acquired from Intermagnetic General Corp. (IGC). A total of 78 samples for the winding of the first cable and 11 samples for the winding of the second cable were measured. These 1"-long samples were tested in $\mathrm{LN}_{2}$ with up to 0.5 - $\mathrm{T}$ magnetic field parallel and perpendicular to the wide

Manuscript received August 26, 1996

Research performed under a CRADA between Southwire and ORNL. the latter is sponsored by the Office of Energy Efficiency and Renewable Energy, U.S. Department of Energy under contract DE-AC05-960R22464 with Lockeed Martin Energy Research, Inc.

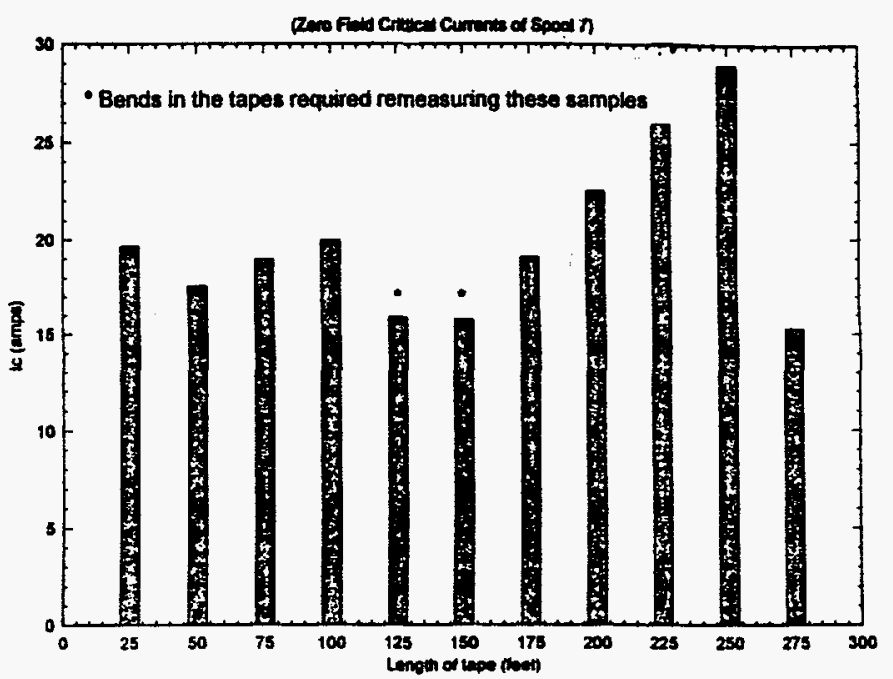

Fig. 1 Zero-fieid short sample critical currents along the length of the tape for use in cable $\$ 2$.

face of the tape. Figure 1 shows the measured zero-field short sample critical currents, $I_{c}$ (at the $1 \mu \mathrm{V} / \mathrm{cm}$ criterion) along the length of the spool used to wind the second cable. It can be seen that $I_{c}$ varies significantly (by a factor of two) along the length of the tape. A mean $I_{c}$ value of $20 \mathrm{~A}$ was measured, as compared to the end-to-end value of $17 \mathrm{~A}$. Similarly, a mean $I_{c}$ value of $19 \mathrm{~A}$ was measured for the tapes used to wind the first cable, as compared to the end-to-end value of $12 \mathrm{~A}$. Apparently, damaged spots on a large spool were apt to be skipped when short samples (of about 1 "-long) were taken.

As is well known, magnetic fields degrade[2] the Bi$2223 / \mathrm{Ag}$ HTS tapes significantly at $\mathrm{LN}_{2}$ temperatures. At a background field value of $0.01 \mathrm{~T}$, the present tapes showed an average of $10 \%$ degradation in $I_{c}$ with field parallel to the wide face and $50 \%$ degradation with field perpendicular to the wide face of the tape.

Bending tests were performed on selected samples of the HTS tapes. In a series of tests, I-V curves of 3"-long samples were measured before and after wrapped around a 1 "-diameter former side-by-side. Figure 2 Shows the comparison of the $I_{c} s^{\prime}$ measured in straight (before wrapping) and in wrapped condition from two different spools. The samples from the lower $I_{c}$ spool showed an average degradation of $30 \%$ and those from the higher $I_{c}$ spool showed an average degradation of $53 \%$. 


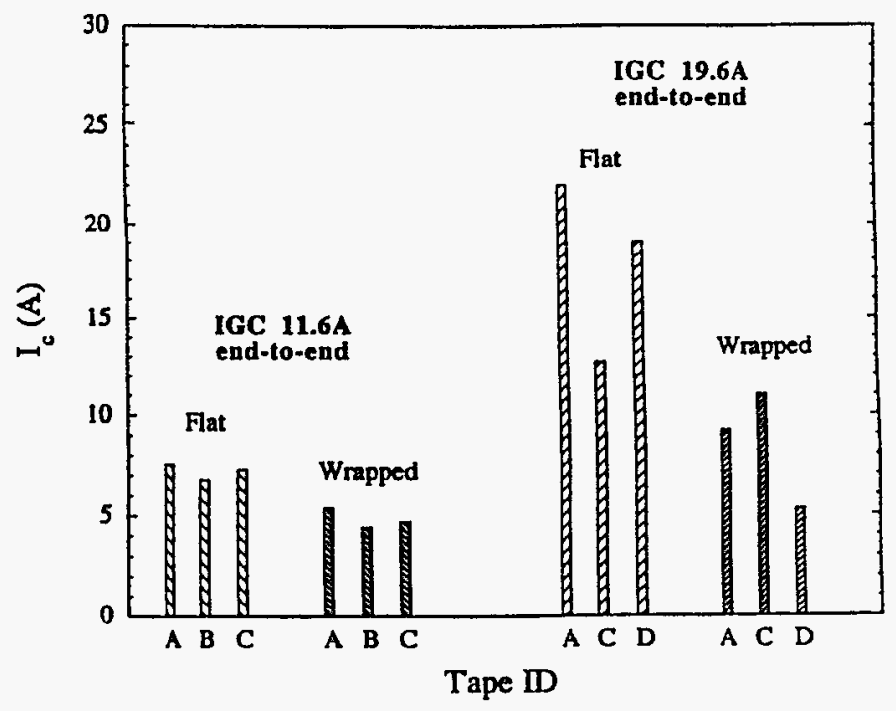

Fig. 2 Comparison of $I_{s} s^{\prime}$ before and after wrapped around a 1 "-diameter tormer.

Bending tests were also performed with samples of about $30-\mathrm{cm}$ long wrapped with lay angles of up to $30^{\circ}$. Between 40 to $50 \%$ of $I_{c}$ degradation were observed as compared to the $I$ "long short sample values.

\section{PROTOTYPE CABLES}

Two prototype transmission cables were fabricated by Southwire using the $3.5 \mathrm{~mm} \times 0.22 \mathrm{~mm}$ HTS tapes tested above. The $1.2-\mathrm{m}$ long cables were made by spirally winding the tapes on a $22-\mathrm{mm}(7 / 8$ ") copper former.

For the first cable, no insulation was used to electrically separate the tapes. The ends of the tapes on the first layer were soldered onto the former. Successive layers were wound with alternating twist angles, and the ends soldered to the previous layer. A total of 73 tapes were wound in four layers in the first cable. Figure 3 shows a picture of the cable assembled and ready to be lowered into the test dewar. The main body of the cable was enclosed in a micarta pipe filled with wax for the purpose of establishing adiabatic conditions to measure the temperature rise (and thus the ac loss) of the cable.

Cable \#2 was fabricated in a way similar to the first cable, except that the tapes on each layer were separated from each other and Kapton tape was used between layers for insulation. A total of 66 tapes was used in the second cable.

\section{DC CURRENT MEASUREMENTS}

The electrical tests of the cables were carried out in $\mathrm{LN}_{2}$ with the HTS cable held upright in a 1.6-m deep dewar.

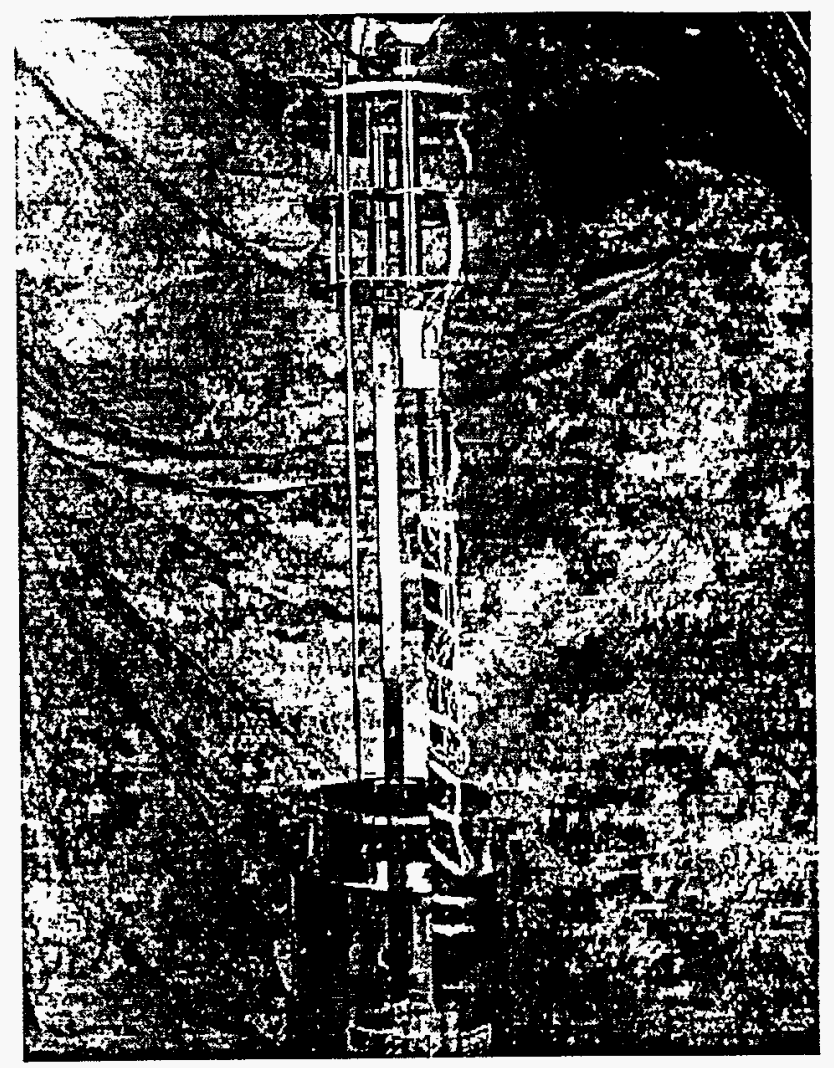

Fig. 3. Picture of cable $\# 1$ assembled for testing with DC and AC currents.

\section{A. DC I-l' of Cable \#I}

Four voltage taps were placed on the cable, separating by about $30 \mathrm{~cm}$ each. and labeled as $V_{1}$ to $V_{4}$. Figure 4 shows the $\mathrm{I}-\mathrm{V}$ curves of the different sections of the cable and the whole cable. $V_{\text {Tol }}$. Gradual resistive voltage rise was seen for currents starting at about $400 \mathrm{~A}$. It was also noticed that all resistive voltage of the cable came from the mid-section, $V_{23}$ at currents up to $650 \mathrm{~A}$. This is probably due mainly to a visible damage near the middle of the cable. Nevertheless, the overall critical current of $670 \mathrm{~A} @$ the $1 \mu \mathrm{V} / \mathrm{cm}$ criterion is still higher than the design value of $500 \mathrm{~A}$.

\section{B. DC I-V of Cable \#2}

The layers of cable \#2 were insulated from each other with Kapton tape and separate current leads were brought out for each layer. Thus this cable can be tested as a whole or on individual layers, separately. When the cable as a whole was tested, an $I_{c}$ of $560 \mathrm{~A}$ was measured. Notice also that because of the broad resistive transition, both cable $\# 1$ and $\# 2$ can be operated stably at more than I kA.

During the test of the outermost layer of cable $\# 2$, the liquid nitrogen bath was also pumped to lower the temperature. Figure 5 shows the I-V curves of this layer at three different 

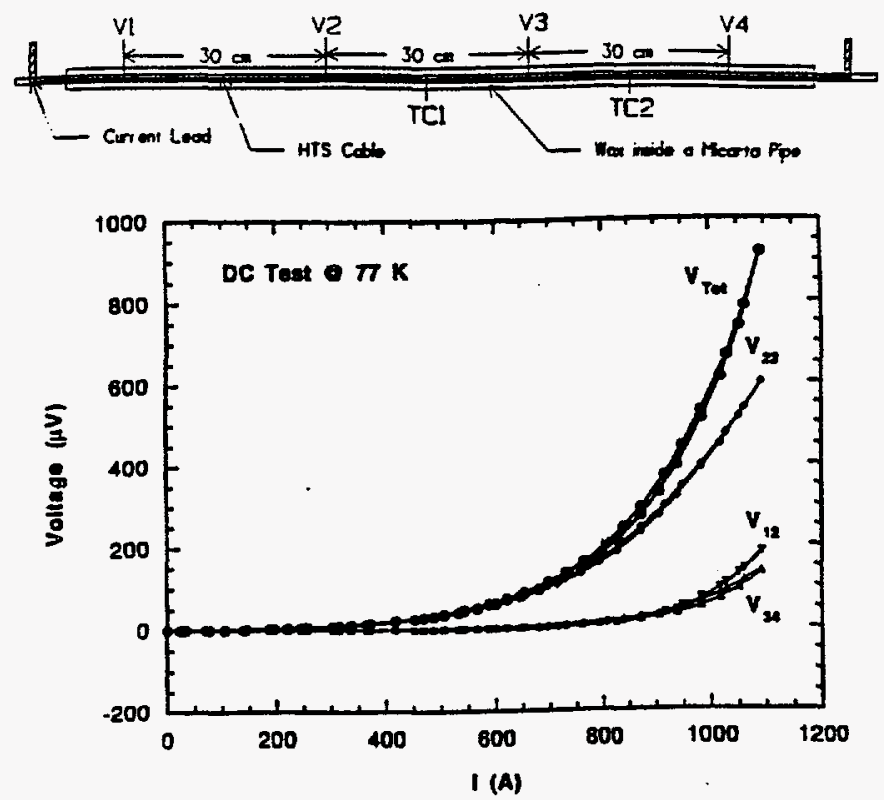

Fig. 4 DC I-V curves of Cable \#1 at the first cooldown.

temperatures of the $\mathrm{LN}_{2}$ bath. The $\mathrm{I}_{\mathrm{c}}$ of this layer has increased from 149 to $186 \mathrm{~A}$ when the bath temperature was lowered from 77 to $69 \mathrm{~K}$. Thus an increase of about $25 \%$ in current carrying capability can be achieved in the cable by operating with subcooled $\mathrm{LN}_{2}$ in a decreased temperature of about $69 \mathrm{~K}$.

\section{Thermal Cycle of Cable \#1}

After a few cycles of cooling down and warming up of cable \#1 for DC and AC current measurements, a series of continuous thermal cycle test was also performed for the cable.

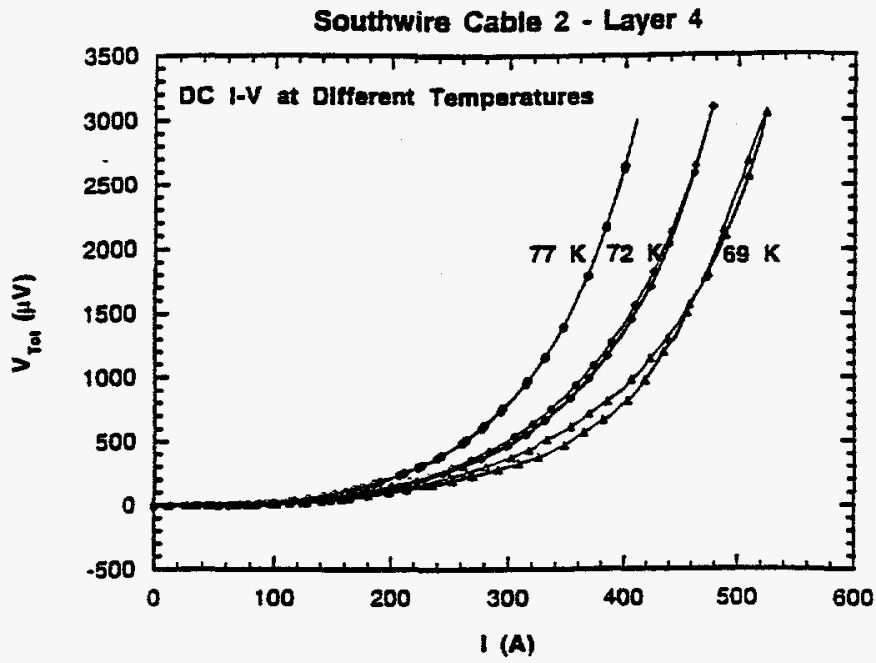

Fig. 5 I-V curves of the outermost layer of cable $\# 2$ at three different bath temperatures.

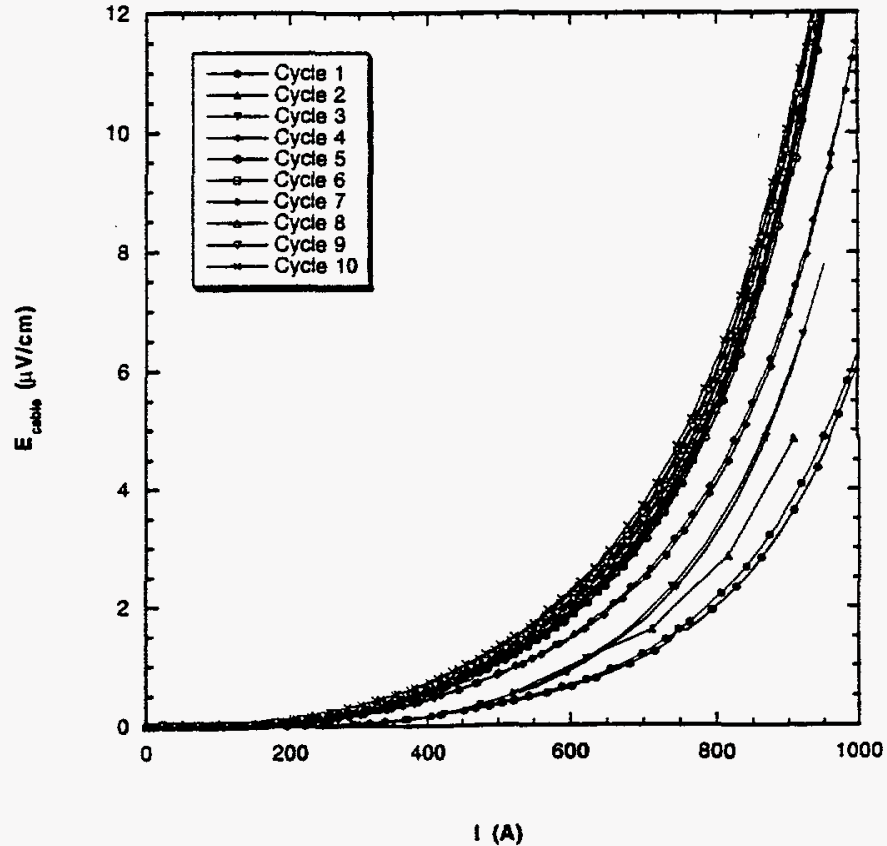

Fig. 6 I-E curves of cable \#l on successive thermal cycies.

An I-V curve was measured, and the cable was pulled out of the $\mathrm{LN}_{2}$ bath. After it was warmed up to room temperature in air, the sample was lowered back down to the $\mathrm{LN}_{2}$ bath Another I-V curve was measured. Figure 6 shows a series of these I-V curves at different thermal cycles. Significant degradation was observed on thermal cycling. However, the degradation seems to level off after the 5 th cycle. Critical current of the cable was decreased from 670 to $460 \mathrm{~A}$ after 10 thermal cycles - a $30 \%$ degradation. Power law fitting of the $\mathrm{I}-\mathrm{V}$ curves between 0.2 to $2 \mu \mathrm{V} / \mathrm{cm}$ also shows a decrease of $\mathrm{n}$ value from 3.5 to 2.6 .

\section{Comparison of Short Sample and Cable $I_{c}$}

The measured $I_{c}$ per tape of cable $\# 1$ and $\# 2$ averages about 8.8 A. This is significantly lower than the average short sample value of 19.5 A measured on 1 "-long short samples. As is described in the series of short sample measurements, several mechanisms can contribute to the degradation of the cable $\mathrm{I}_{c}$. The short sample $I_{c}$ measurements can be misleading, because it could skip bad spots on the long lengths of the tape. Mechanical strain similar to that applied in winding the cable can degrade[3] the $I_{c}$ by about $50 \%$. This can come from just handling the long lengths of the tape and from the bending applied in the cabling. The magnetic field degradation by the cable self field is well known. Finally, thermal cycling degradation was also observed.

\section{AC CURRENT MEASUREMENTS}

Both cable $\# 1$ and $\# 2$ were tested with $60 \mathrm{~Hz}$ ac currents up to $600 \mathrm{~A}$ rms. Steady rms voltages were observed at all test 
currents. To measure the ac loss of the cable at the applied ac currents, a calorimetric technique was adopted. As is shown in Fig. 3 a micarta pipe filled with wax was used to thermally isolate the cable from the $\mathrm{LN}_{2}$ bath. A Cromel-Constantan thermocouple was attached to the middle of the cable to measured its temperature rise against $\mathrm{LN}_{2}$ at the same depth of the bath. Temperature rise of up to $0.3 \mathrm{~K}$ was observed in the present tests.

To calibrate the temperature rise against the power loss rate, we used the broad resistive transition feature of the HTS cable itself. The cable was charged and held at a dc current above its $\mathrm{I}_{\mathrm{c}}$ where a resistive voltage can be measured. A temperature rise, $\Delta \mathrm{T}$ of the cable was also measured under this dc current. The dc E.I product gave the average power loss for the measured $\Delta \mathrm{T}$. This technique was found to be better than the heater wires tried on cable \#1.

Figure 7 shows the measured ac losses of the two cables as a function of the rms current. Also shown in this figure are the two cables' respective dc I-E curve for reference. The uninsulated cable \#1 behaved like a cryoresistive conductor, showing power loss at all ac currents. Similar behavior was reported by Gannon et al. [4]. The insulated cable \#2 showed no measurable ac loss until about $300 \mathrm{~A} \mathrm{rms}$, where the cable also started to show measurable dc resistive voltage. An average ac loss of about $0.2 \mathrm{~W} / \mathrm{m}$ was measured at $400 \mathrm{~A}$ rms. Analysis of the loss data indicated that the measured loss is governed by the power law behavior of the HTS tape in the resistive transition[5].

\section{SUMMARY}

Two prototype high-temperature superconducting cables have been designed, constructed, and tested. Both cables achieved DC critical currents greater than the design value of $500 \mathrm{~A}$. Furthermore, because of the broad resistive transition, they can be operated stably at more than $1 \mathrm{kA}$.

Comparison of the cable $I_{c}$ and the short sample values indicated a degradation of about $55 \%$. Several mechanisms were identified as the probable cause of the degradation. Mechanical strain from handling the long lengths of the tape and from bending applied in winding the cable is thought to be the biggest source of degradation.

A calorimetric technique was used to measure ac losses of the cables. A scheme of utilizing the broad resistive transition of the HTS cable was successfully used to calibrate the loss rate. Loss measurements made on the cables with $60 \mathrm{~Hz}$ ac currents showed that insulation between the tapes is effective in reducing the ac loss of the cable.

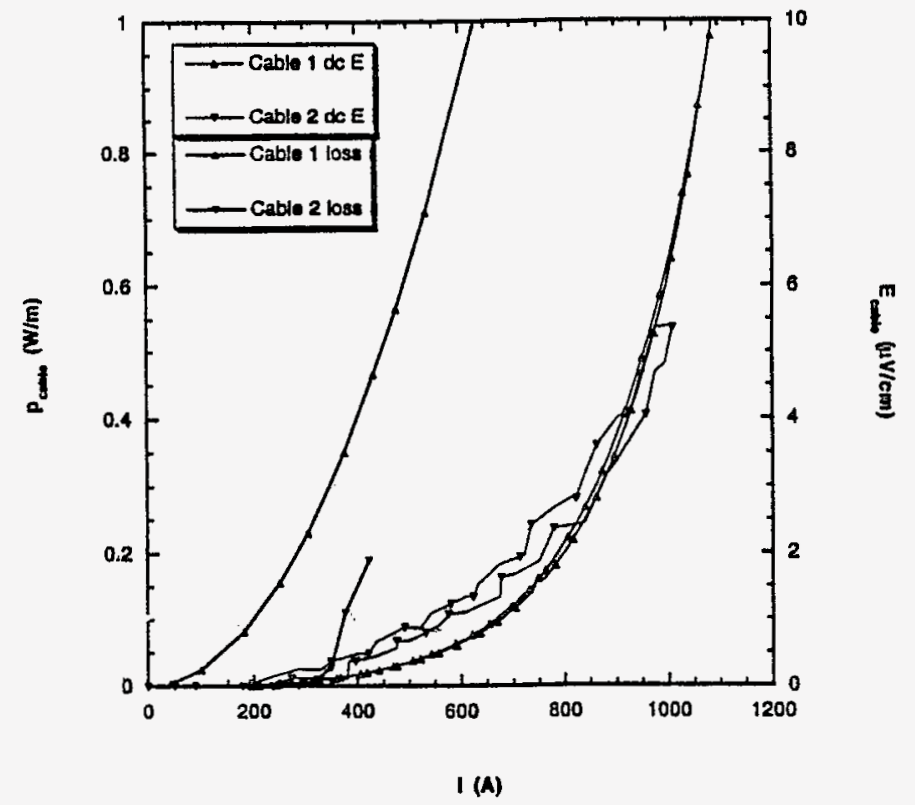

Fig. $7 \mathrm{AC}$ losses of both cable\#I and $\# 2$ in reference to their DC I-E curve. RMS current is plotted for the AC current.

\section{REFERENCES}

U. Sinha. R. L. Hughey, R. A. Hawsey, M. S. Lubell, and J. W. Lue, "Design and construction of $\mathrm{LN}_{2}$-cooled prototype superconducting transmission cable," paper presented at this conference.

M. P. Maley et al. "Behavior of critical currents in Bi-Pb-Sr-Ca$\mathrm{Cu}-\mathrm{O} / \mathrm{Ag}$ tapes from transport and magnetization measurements: Dependence upon temperature, magnetic field, and field orientation." Physical Review B, 7566-7569, 1992.

[3] J. W. Ekin et al. "Effect of axial strain on the critical current of $\mathrm{Ag}$-sheathed $\mathrm{Bi}$-based superconductors in magnetic fields up to 25 T." Appl. Phys. Lett. Vol. 61(7), 858-860, 1992.

J. J. Gannon Jr. et al. "Performance summary of a 4,000 A high temperature superconducting cable conductor prototype," IEEE Trans. Appl. Supercond. Vol. 5, No. 2, 953-956, 1995. paper submitted to the Applied Superconductivity. 